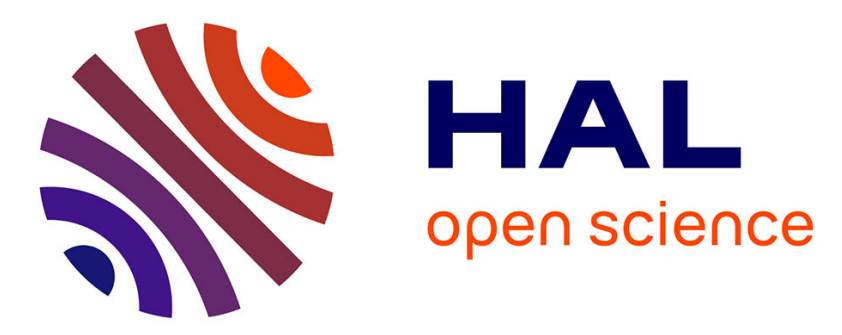

\title{
A 43 Ca NMR perspective on octacalcium phosphate and its hybrid derivatives
}

Danielle Laurencin, Yang Li, Melinda J Duer, Dinu Iuga, Christel Gervais, Christian Bonhomme

\section{- To cite this version:}

Danielle Laurencin, Yang Li, Melinda J Duer, Dinu Iuga, Christel Gervais, et al.. A 43 Ca NMR perspective on octacalcium phosphate and its hybrid derivatives. Magnetic Resonance in Chemistry, 2021, 59, pp.1048. 10.1002/mrc.5149 . hal-03177548

\section{HAL Id: hal-03177548 \\ https://hal.sorbonne-universite.fr/hal-03177548}

Submitted on 23 Mar 2021

HAL is a multi-disciplinary open access archive for the deposit and dissemination of scientific research documents, whether they are published or not. The documents may come from teaching and research institutions in France or abroad, or from public or private research centers.
L'archive ouverte pluridisciplinaire HAL, est destinée au dépôt et à la diffusion de documents scientifiques de niveau recherche, publiés ou non, émanant des établissements d'enseignement et de recherche français ou étrangers, des laboratoires publics ou privés. 
A ${ }^{43} \mathrm{Ca}$ NMR perspective on octacalcium phosphate and its hybrid derivatives

Danielle Laurencin, ${ }^{1 *}$ Yang Li, ${ }^{2}$ Melinda J. Duer, ${ }^{2 *}$ Dinu luga, ${ }^{3}$ Christel Gervais, ${ }^{4}$

Christian Bonhomme ${ }^{*}$

${ }^{1}$ ICGM, Univ Montpellier, CNRS, ENSCM, Montpellier, France.

${ }^{2}$ Department of Chemistry, University of Cambridge, Lensfield Road, Cambridge, Cambs, CB2 1EW, United Kingdom.

${ }^{3}$ Department of Physics, University of Warwick, Gibbet Hill Road, Coventry CV4 7AL, United Kingdom.

${ }^{4}$ LCMCP - Laboratoire de Chimie de la Matière Condensée de Paris, Sorbonne Université, 4 place Jussieu, 75252 Paris Cedex 05, France.
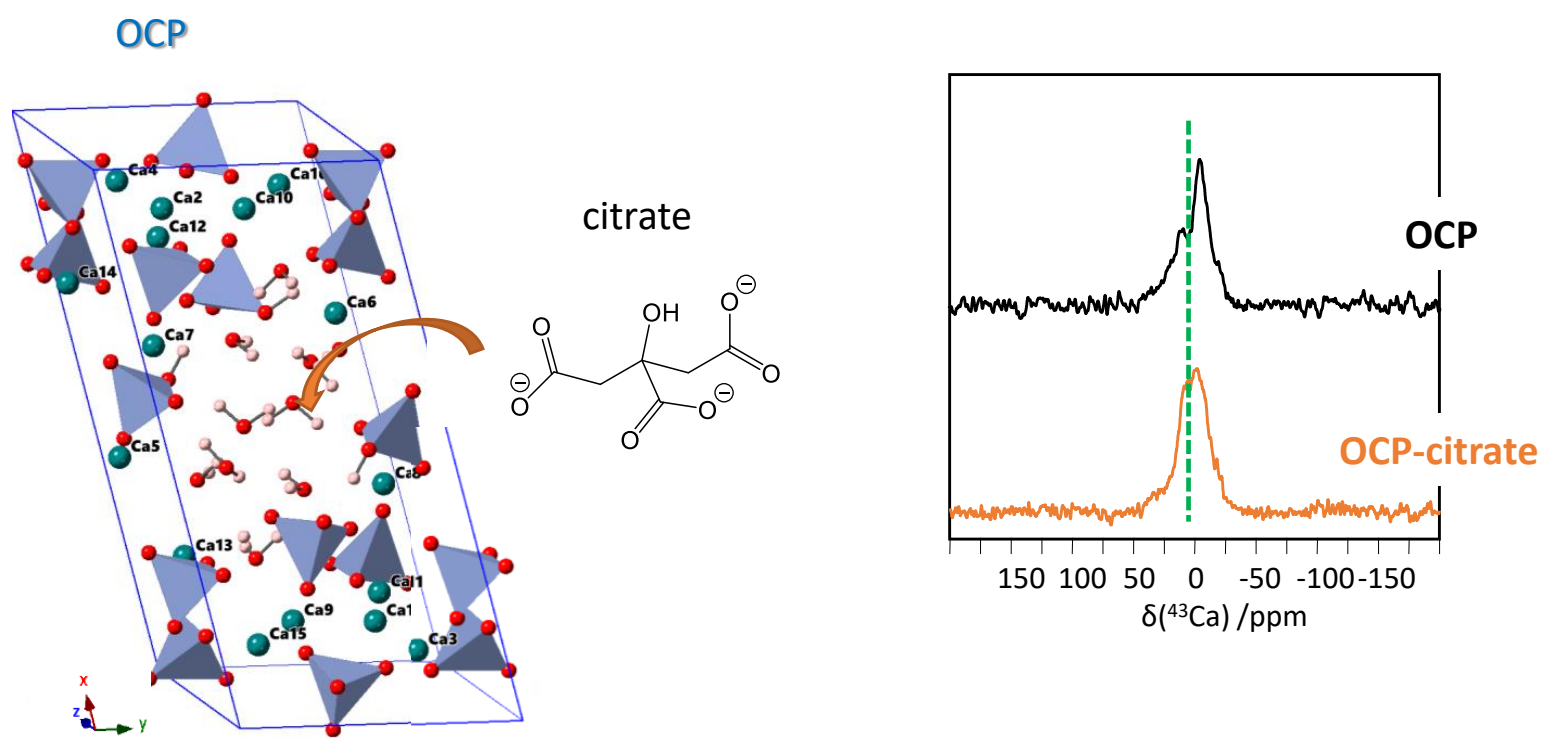


\section{Abstract}

${ }^{43}$ Ca NMR spectroscopy has been extensively applied to the detailed study of octacalcium phosphate (OCP), $\mathrm{Ca}_{8}\left(\mathrm{HPO}_{4}\right)_{2}\left(\mathrm{PO}_{4}\right)_{4} \cdot 5 \mathrm{H}_{2} \mathrm{O}$, and hybrid derivatives involving intercalated metabolic acids (namely citrate, succinate, formate, and adipate). Such phases are of importance in the development of a better understanding of bone structure. High resolution

${ }^{43} \mathrm{Ca}$ MAS experiments, including double-rotation (DOR) ${ }^{43} \mathrm{Ca} N M R$, as well as ${ }^{43} \mathrm{Ca}\left\{{ }^{1} \mathrm{H}\right\}$ REDOR and ${ }^{31} P\left\{{ }^{43} \mathrm{Ca}\right\}$ REAPDOR NMR spectra were recorded on a ${ }^{43} \mathrm{Ca}$-labeled OCP phase at very high magnetic field $(20 \mathrm{~T})$, and complemented by ab initio calculations of NMR parameters using the GIPAW-DFT method. This enabled a partial assignment of the 8 inequivalent $\mathrm{Ca}^{2+}$ sites of OCP. Natural-abundance ${ }^{43} \mathrm{Ca}$ MAS NMR spectra were then recorded for the hybrid organic-inorganic derivatives, revealing changes in the ${ }^{43} \mathrm{Ca}$ lineshape. In the case of the citrate derivative, these could be interpreted on the basis of computational models of the structure. Overall, this study highlights the advantages of combining high-resolution ${ }^{43} \mathrm{Ca} N M R$ experiments and computational modeling for studying complex hybrid biomaterials.

KEYWORDS. ${ }^{43}$ Ca solid state NMR, quadrupolar nuclei, octa-calcium phosphate $\mathrm{Ca}_{8}\left(\mathrm{HPO}_{4}\right)_{2}\left(\mathrm{PO}_{4}\right)_{4} .5 \mathrm{H}_{2} \mathrm{O}$, hybrid organic-inorganic composites, metabolic acids, biomaterials. 


\section{INTRODUCTION: RECENT TRENDS IN ${ }^{43}$ Ca SOLID STATE NMR}

The elements in the second column of the periodic table (alkaline earth) are of particular importance in materials science as well as in the more specific field of biomaterials. Curiously, all the stable magnetically active isotopes of these elements are quadrupolar in nature $(I>1 / 2)$ (see Table 1). The NMR characteristics of each nucleus vary greatly from one element to the other both in terms of natural abundance (from $0.14 \%$ for ${ }^{43} \mathrm{Ca}$ to $100 \%$ for ${ }^{9} \mathrm{Be}$ ) and associated quadrupolar moments.

\begin{tabular}{|c|c|c|c|c|c|}
\hline Nucleus & I & Natural & Quadrupole & Larmor frequency & Gyromagnetic ratio \\
& & Abundance (\%) & moment $\left(\mathrm{fm}^{2}\right)$ & $(\mathrm{MHz})$ & $\left(10^{7}{\left.\mathrm{rad} . \mathrm{s}^{-1} . \mathrm{T}^{-1}\right)}\right.$ \\
\hline${ }^{1} \mathrm{H}$ & $1 / 2$ & 99.9885 & - & 850.130 & 26.7522 \\
\hline${ }^{9} \mathrm{Be}$ & $3 / 2$ & 100.0 & 5.288 & 119.459 & -3.7606 \\
\hline${ }^{25} \mathrm{Mg}$ & $5 / 2$ & 10.0 & 19.94 & 52.042 & -1.6389 \\
\hline${ }^{43} \mathrm{Ca}$ & $7 / 2$ & 0.135 & -4.08 & 57.214 & -1.8028 \\
\hline${ }^{87} \mathrm{Sr}$ & $9 / 2$ & 7.00 & 30.5 & 36.843 & -1.1635 \\
\hline${ }^{135} \mathrm{Ba}$ & $3 / 2$ & 6.592 & 15.3 & 84.456 & 2.6755 \\
\hline${ }^{137} \mathrm{Ba}$ & $3 / 2$ & 11.232 & 23.6 & 94.474 & 2.9930 \\
\hline
\end{tabular}

Table 1: Stable magnetically active isotopes for alkaline earths (comparison with ${ }^{1} \mathrm{H}$ ). The data are extracted partly from ${ }^{1}$.

As a result, the NMR spectroscopist must adapt the solid-state NMR methodology to optimize the sensitivity of the NMR experiment by using the latest advances in instrumentation and sequence development. Considering for example ${ }^{87} \mathrm{Sr}^{2}{ }^{2}$ which is an important element in the 
context of materials against osteoporosis (including bioglasses): ${ }^{3}$ as shown in Table 1 , it is a nucleus of moderate natural abundance, with a very low gyromagnetic ratio and a high quadrupole moment. This generally results in strongly broadened central transitions (due to second order quadrupolar interaction), making standard sample rotation techniques such as fast MAS (Magic Angle Spinning) or MQ-MAS (Multiple-Quantum Magic Angle Spinning) totally ineffective. Static mode experiments combining: (i) the use of the highest $B_{0}$ magnetic fields and large volume rotors, (ii) the WURST-QCPMG (Wideband Uniform Rate Smooth Truncation - Quadrupolar Carr-Purcell Meiboom-Gill) approach, ${ }^{4}$ (iii) the DFS (Double-Frequency Sweep) ${ }^{5}$ or multi-DFS (m-DFS) ${ }^{6}$ signal-enhancement scheme, are to be preferred. The case of ${ }^{43} \mathrm{Ca}$ is radically different. Since the pioneering work of Dupree et $a l .{ }^{7}{ }^{7}$ it has been widely demonstrated that rotation of the sample at a moderate rotation frequency ( 4 to $5 \mathrm{kHz}$ ) at a high magnetic field ( $\geq 14 \mathrm{~T}$ ) is largely sufficient in the vast majority of cases to recover isotropic signals, weakly broadened by the quadrupole second order interaction. Very recently, it has been shown that at ultra-high magnetic field (35.2 T, which corresponds to a Larmor frequency of $100.96 \mathrm{MHz}$ for $\left.{ }^{43} \mathrm{Ca}\right),{ }^{8}$ the ultimate high resolution in ${ }^{43} \mathrm{Ca}$ can even be reached in some cases. The main problem of ${ }^{43} \mathrm{Ca}$ solid phase NMR remains the very low sensitivity due to both the very low natural abundance $(0.14 \%)$ and the low gyromagnetic ratio. Nevertheless, over the last fifteen years, ${ }^{43} \mathrm{Ca}$ NMR has experienced very strong developments including for natural abundance ${ }^{43} \mathrm{Ca} .{ }^{9,10}$ In this case, it is necessary to use large MAS rotors (from 7.0 to $9.5 \mathrm{~mm}$ ) and the highest accessible magnetic fields in order to maximize sensitivity. It should be kept in mind that for a magnetic field of $20.0 \mathrm{~T}\left(850 \mathrm{MHz}\right.$ for $\left.{ }^{1} \mathrm{H}\right), 300$ to $500 \mathrm{mg}$ of sample containing $>10 \mathrm{wt} \%$ calcium are generally required to obtain a 1D MAS spectrum of acceptable signal-to-noise ratio in approximately 3 to 10 hours approximately, although of course this depends on $\mathrm{T}_{1}\left({ }^{43} \mathrm{Ca}\right)$ relaxation times. Another possibility to get around the intrinsic problem 
of sensitivity is isotopic enrichment in ${ }^{43} \mathrm{Ca}$. A well-known source, calcium carbonate, ${ }^{*} \mathrm{CaCO}_{3}$ (calcite type), is commercially available. Synthesizing ${ }^{43} \mathrm{Ca}$-enriched compounds from this can include ${ }^{*} \mathrm{CaO}$ oxide by heat treatment. ${ }^{11}$ The advantages in terms of NMR spectroscopy are then numerous: (i) the implementation of high-resolution methods dedicated to quadrupolar nuclei in 1D (DOR, DOuble Rotation) ${ }^{12}$ or 2D (MQ-MAS), ${ }^{13}$ (ii) the possible implementation of heteronuclear correlation methods in $1 \mathrm{D}$ and $2 \mathrm{D},{ }^{43} \mathrm{Ca}-\mathrm{X}$ ( $\mathrm{X}$ with $\mathrm{I}=1 / 2$ generally) to evaluate spatial proximities and internuclear distances, ${ }^{9}$ (iii) the study of very small masses of sample with adapted instrumental systems such as micro-coils under MAS. ${ }^{14}$ Of course, two major disadvantages of this approach must be mentioned, namely the very high price of enrichment $\left(62 \%{ }^{43} \mathrm{Ca}\right.$ labeled ${ }^{*} \mathrm{CaCO}_{3}$ costs $\approx 1500 €$ per $10 \mathrm{mg}$ ) and obviously, the near-impossibility of studying natural samples.

Among very recent applications of ${ }^{43} \mathrm{Ca}$ NMR for synthetic samples one can highlight: (1) The precise determination of the calcium environment in atorvastatin calcium which corresponds to the active pharmaceutical ingredient of Lipitor (against high blood plasma low density lipoprotein cholesterol and triglycerides and hypertension). ${ }^{15}$ This study makes extensive use of the NMR crystallography approach which was initiated by Bryce and Gervais et al. in $2008 .{ }^{16,17}$ All ${ }^{43}$ Ca NMR parameters $\left(\delta_{\text {iso, }}\right.$ CSA, quadrupolar interaction, Euler angles between CSA and EFG, Electric Field Gradient - tensors) were used as constraints for local structural determination (here in absence of XRD data). The approach was then extended to a solvate (ethylene glycol) of atorvastatin calcium. It is worth mentioning here for NMR crystallography, utilizing ${ }^{43} \mathrm{Ca}$ parameters, that a recent study also compared different theoretical methods to calculate NMR parameters such as Hartree-Fock theory and more than 15 DFT approaches ${ }^{18}$ to calculate NMR parameters with special attention to the calculation of 
${ }^{43} \mathrm{Ca}$ CSA tensors. (2) The use of ${ }^{43} \mathrm{Ca} \mathrm{NMR}$ to the study of some biocompatible calcium-containing MOFs. ${ }^{19}$ It was shown that ${ }^{43} \mathrm{Ca}$ NMR could demonstrate the presence of guest molecules in the local environment of calcium atoms. Once again, in the absence of XRD data, NMR acts as a powerful technique to demonstrate host-guest interactions. In the particular case of MIL-121 and loading with $\mathrm{Ca}^{2+}$, detailed characterization was performed by ${ }^{43} \mathrm{Ca} \mathrm{NMR} .{ }^{20}$ (3) The study by natural abundance ${ }^{43} \mathrm{Ca}$ NMR in natural abundance of bioceramic materials based on silico-carnotite, $\mathrm{Ca}_{5}\left(\mathrm{PO}_{4}\right)_{2} \mathrm{SiO}_{4}$, synthesized mechano-chemically. Calculated $\delta_{\text {iso }}\left({ }^{43} \mathrm{Ca}\right)$ were used to analyze carefully the experimentally-determined results. ${ }^{21}$ ${ }^{43} \mathrm{Ca} N \mathrm{NM}$ is also very informative in the study of natural compounds (in natural abundance). Examples include kidney stones, bones and teeth. The mineral part of human kidney stones is essentially composed of calcium oxalate monohydrate $\left(\mathrm{CaC}_{2} \mathrm{O}_{4} \cdot \mathrm{H}_{2} \mathrm{O}\right)$ and more rarely of calcium oxalate dihydrate $\left(\mathrm{CaC}_{2} \mathrm{O}_{4} \cdot 2 \mathrm{H}_{2} \mathrm{O}\right)$. The third hydrate, $\mathrm{CaC}_{2} \mathrm{O}_{4} \cdot 3 \mathrm{H}_{2} \mathrm{O}$, is almost absent. Apatitic components (see below) can be observed as well. While synthetic calcium oxalates and kidney stones have been studied mainly by ${ }^{1} \mathrm{H}$ and ${ }^{13} \mathrm{C}$ solid state NMR, Wong et al. ${ }^{22}$, Bowers et al. ${ }^{23}$ and Colas et al. ${ }^{24}$ have shown that ${ }^{43} \mathrm{Ca}$ MAS NMR spectra of synthetic and natural compounds can also be obtained in natural abundance.

Another Ca-containing mineral of considerable interest is hydroxyapatite (HAp), $\mathrm{Ca}_{10}\left(\mathrm{PO}_{4}\right)_{6}(\mathrm{OH})_{2}$, which is related to the major inorganic component in mammalian bones and teeth. In mineralized tissues, apatitic mineral is usually partially substituted, especially by carbonates. Numerous ${ }^{1} \mathrm{H},{ }^{31} \mathrm{P}$ and ${ }^{13} \mathrm{C}$ NMR studies related to natural and biomimetic calcium phosphate phases have been published. These include ${ }^{13} \mathrm{C}-{ }^{31} \mathrm{P}$ REDOR, Rotational Echo Double Resonance $25,26,27,28,29$ to study the interfaces between the mineral part of bone (crystalline hydroxyapatite-related and non-apatitic, amorphous components) and the organic part (collagen and other organic molecules). Within the topic of the organic-inorganic interface in 
bone, OCP, $\mathrm{Ca}_{8}\left(\mathrm{HPO}_{4}\right)_{2}\left(\mathrm{PO}_{4}\right)_{4} .5 \mathrm{H}_{2} \mathrm{O}$, occupies a very special position. Its role as a potential precursor phase of biological HAp has been evoked in the literature. ${ }^{30}$ The OCP atomic structure contains apatitic layers, sandwiched by hydrated layers (Figure 1). It has been demonstrated that citrate anions may bridge the mineral platelets in bones. ${ }^{26,31}$ Moreover, it is also well established that other metabolic acids can be present in bone. The OCP atomic structure is capable of intercalating all of these metabolic acid species, making OCP an interesting calcium phosphate phase in which to study the incorporation of metabolic anions in bone mineral. Some of the biologically-relevant anions are presented in Figure 1.

\section{OCP unit cell}

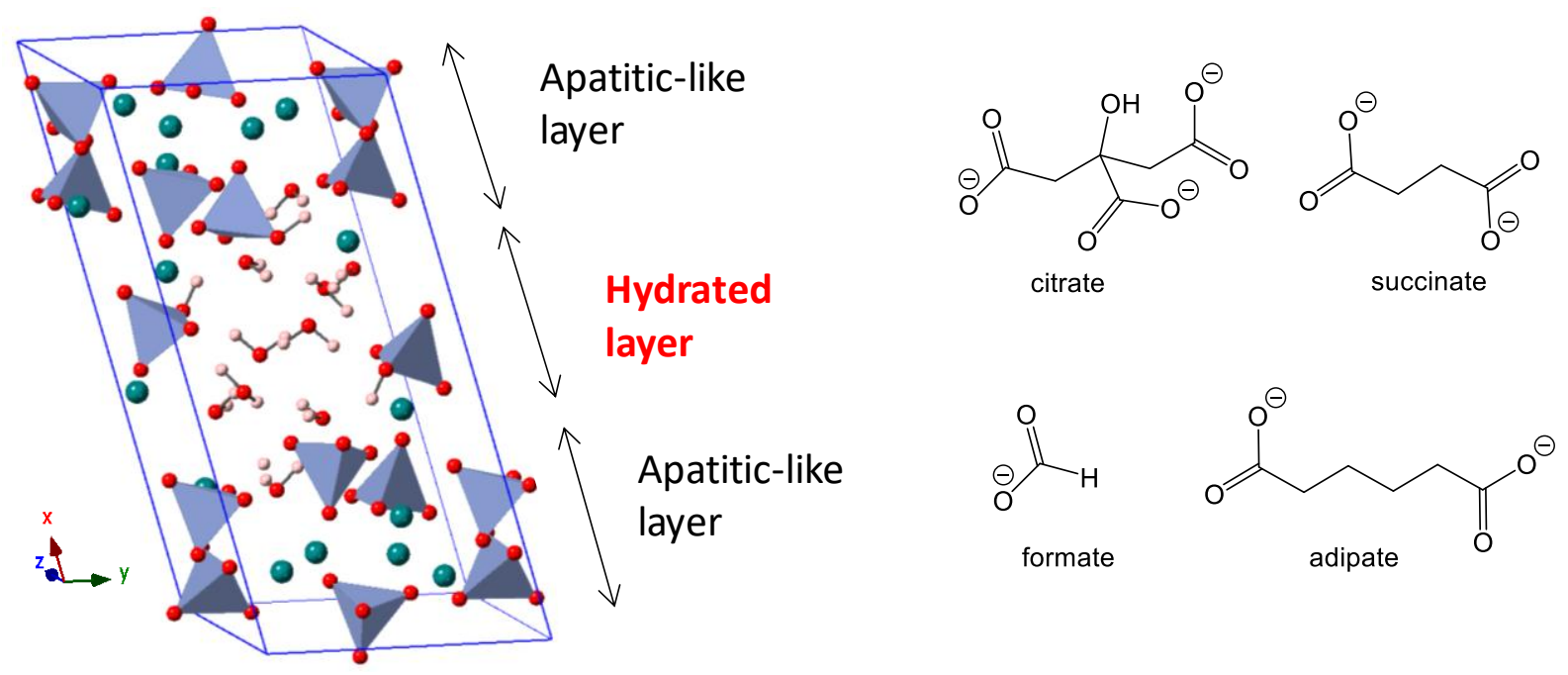

Figure 1. OCP structure and a selection of metabolic acids potentially incorporated in bone. The incorporation of these metabolic acids in bone mineral are modelled as interaction in the hydrated layer of an OCP component. $\mathrm{H}$ : light pink, Ca: green, O: red, $\mathrm{PO}_{4}^{3-}$ : blue tetrahedral. The weight percentages of the different metabolic acids in bone vary according to animal age: fetal bone, which is much softer than adult bone, contains very large quantities of lactate, ${ }^{32}$ 
whereas in adult bone, the quantity of citrate is directly related to bone mineral quality. ${ }^{33}$ Currently, the role and characterization of metabolic acids in bone is very poorly understood as well as their underlying role in biomineralization.

In this contribution, we explore the potential of using ${ }^{43} \mathrm{Ca} N \mathrm{NM}$ to study the structure of synthetic OCP and related hybrid phases, both at natural abundance and on enriched samples. For OCP, we show how the study of a ${ }^{43} \mathrm{Ca}$ labeled sample enabled advanced experiments, such as DOR and heteronuclear ${ }^{43} \mathrm{Ca}\{\mathrm{X}\}$ REDOR and $\mathrm{X}\left\{{ }^{43} \mathrm{Ca}\right\}$ REAPDOR correlations $\left(\mathrm{X}={ }^{1} \mathrm{H}\right.$ and

${ }^{31} \mathrm{P}$, respectively). We calculated ${ }^{43} \mathrm{Ca}$ NMR parameters for OCP by first principles calculations (GIPAW method, Gauge-Including Projector Augmented Wave), to compare with the experimental parameters. These calculations follow those proposed in 2012 by Duer et al. for ${ }^{31} \mathrm{P} .{ }^{31}$ In a second step, we studied several intercalated hybrid OCPs containing metabolic acids relevant to bone mineral (citrate, succinate, formate, adipate and mixed citrate/formate ions). We demonstrate that ${ }^{43} \mathrm{Ca}$ MAS NMR allowed two families of hybrid compounds with different intrinsic structures to be distinguished in a very simple way. In a third and last step, the OCP-citrate hybrid compound was investigated in more detail using NMR crystallography and considering five computational models of this phase.

\section{SAMPLE PREPARATION AND ${ }^{43}$ Ca NMR METHODS}

\subsection{Syntheses of OCP and OCP hybrid materials.}

The general procedure is already reported in a previous contribution by Duer et al. ${ }^{27}$ Briefly, OCP was synthesized by reaction of $\mathrm{CaCO}_{3}(1.604 \mathrm{~g}, 16 \mathrm{mmol})$ with $\mathrm{H}_{3} \mathrm{PO}_{4}(0.6 \mathrm{ml}, 10 \mathrm{mmol})$ in $200 \mathrm{~mL}$ of water at $60{ }^{\circ} \mathrm{C}$ without any control of the $\mathrm{pH}$ (reagents were purchased from 
Sigma-Aldrich and used as received). In the case of OCP-metabolic acid derivatives (involving citrate, succinate, formate, adipate and mixed citrate/formate ions), the relevant organic acid was dissolved in water $(200 \mathrm{~mL})$ at $\mathrm{pH}=5.5$ by addition of $\mathrm{NaOH}$ (dropwise). After heating at $60{ }^{\circ} \mathrm{C}$ (under stirring), $\mathrm{CaCO}_{3}$ and $\mathrm{H}_{3} \mathrm{PO}_{4}$ (quantities as mentioned above) were added to the aqueous solutions. White powders were collected after 6 hours by filtration and dried in air. All samples were analyzed by elemental analyses and powder XRD. ${ }^{27}$

\section{2. ${ }^{43} \mathrm{Ca}$ NMR spectroscopy.}

OCP and intercalated hybrid OCP phases were studied using natural abundance ${ }^{43} \mathrm{Ca}$ NMR experiments, which were acquired at $20.0 \mathrm{~T}$ on a Bruker Avance III-850 (850 MHz ${ }^{1} \mathrm{H}$ frequency) spectrometer operating at ${ }^{43} \mathrm{Ca}$ Larmor frequency of $57.22 \mathrm{MHz}$, using a low- $\gamma$ $7 \mathrm{~mm}$ Bruker MAS probe spinning at $5 \mathrm{kHz}$. For the OCP phase, a RAPT (Rotor Assisted Population Transfer) enhancement scheme ${ }^{34}$ was used (offset of $150 \mathrm{kHz}, \mathrm{RF} \sim 9 \mathrm{kHz}$ ), followed by a $90^{\circ}$ selective solid pulse of $1.7 \mu \mathrm{s}$. A total of 137864 transients were acquired, with a recycle delay of $0.5 \mathrm{~s}$. For all intercalated hybrid OCP samples, a multi-DFS (double frequency sweep $)^{5,13}$ enhancement scheme followed by a $90^{\circ}$ selective pulse of $1.5 \mu \mathrm{s}$, was used which was first optimized on a ${ }^{43} \mathrm{Ca}$-labeled ${ }^{*} \mathrm{CaHPO}_{4}$ (monetite) sample leading to 3 blocks of DFS with a DFS pulse length of $2 \mathrm{~ms}$ ( $\mathrm{RF} \sim 8 \mathrm{kHz}$ ) and a convergence sweep from $400 \mathrm{kHz}$ to $50 \mathrm{kHz}$ ), followed by a $90^{\circ}$ selective pulse of $12.5 \mu \mathrm{s}$ (RF $\sim 5 \mathrm{kHz}$ ). It was clearly demonstrated that m-DFS is highly efficient when compared to RAPT and single-DFS approaches. However, the number of DFS blocks has to be limited to avoid distortions of the lineshapes. A total of 65500 transients were acquired for the intercalated OCP phases (studied at the natural abundance of ${ }^{43} \mathrm{Ca}$ ), with a recycle delay of $0.5 \mathrm{~s}$. All ${ }^{43} \mathrm{Ca}$ chemical shifts were 
referenced at $0.0 \mathrm{ppm}$ to a $1.0 \mathrm{~mol} \cdot \mathrm{L}^{-1}$ aqueous solution of $\mathrm{CaCl}_{2} \cdot{ }^{17}$ Details of the recycle delays, number of transients acquired, and total experimental times needed for each sample can be found in Table S1 (in Supplementary Information). The ${ }^{43} \mathrm{Ca}$-enriched OCP sample was first characterized by MAS, using a $4 \mathrm{~mm} \mathrm{HX}$ probe, spinning at $12.5 \mathrm{kHz}$. A multi-DFS enhancement (3 loops) was used, followed by a $12.0 \mu$ s selective pulse. A total of 10000 transients was acquired, with a shortened recycle delay of $0.1 \mathrm{~s}$ in order to saturate the signal of the ${ }^{*} \mathrm{CaCO}_{3}$ impurity signal ( ${ }^{*} \mathrm{CaCO}_{3}$ was used as ${ }^{43} \mathrm{Ca}$ labeled starting material - see below). The ${ }^{43} \mathrm{Ca}$-enriched OCP was then characterized by DOR with the external rotor spinning at $\sim 1.53 \mathrm{kHz}$, and the internal rotor at $\sim 7.69 \mathrm{kHz}$. A RAPT enhancement scheme was applied (10 RAPT $20 \mu$ s pulses with an offset of $+/-150 \mathrm{kHz}$ were followed by a $5 \mu$ s selective $90^{\circ}$ pulse of about $12.5 \mathrm{kHz}$ ). No ${ }^{1} \mathrm{H}$ decoupling was applied due to the poor ${ }^{1} \mathrm{H}$ RF performance of the DOR probe. A total of 155000 transients were acquired, with a recycle delay of $0.1 \mathrm{~s}$. REDOR and REAPDOR experiments were performed using a $4 \mathrm{~mm} \mathrm{HXY}$ probe tuned to ${ }^{1} \mathrm{H},{ }^{31} \mathrm{P}$ and ${ }^{43} \mathrm{Ca}$. Samples were carefully centered in the middle of the MAS rotors. The ${ }^{43} \mathrm{Ca}\left\{{ }^{1} \mathrm{H}\right\}$ REDOR pulse sequence (with ${ }^{43} \mathrm{Ca}$ detection) is presented in Figure S1. For *OCP (studied at $14 \mathrm{kHz}$ MAS), a $90^{\circ}$ pulse of $3.0 \mu \mathrm{s}\left({ }^{43} \mathrm{Ca}\right)$ was applied and $180^{\circ}$ pulses of $7.0 \mu$ s were applied on the ${ }^{1} \mathrm{H}$ channel. The recycle delay was set to $0.1 \mathrm{~s}$. The number of scans were 40000,48000 and 60000 for 8,12 and 24 recoupling loops, respectively. For *HAp (studied at $14 \mathrm{kHz}$ MAS), a 90 pulse of $3.0 \mu \mathrm{s}\left({ }^{43} \mathrm{Ca}\right)$ was applied and $180^{\circ}$ pulses of $7.0 \mu$ s were applied on the ${ }^{1} \mathrm{H}$ channel. The recycle delay was set to $0.4 \mathrm{~s}$. The number of scans was 10000 for 24 recoupling loops. The ${ }^{31} \mathrm{P}\left\{{ }^{43} \mathrm{Ca}\right\} \mathrm{CP}$ (cross polarization) REAPDOR pulse sequence (with ${ }^{31} \mathrm{P}$ detection) is presented in Figure S1 as well. For *HAp (studied at $14 \mathrm{kHz}$ MAS), a $180^{\circ}$ pulse of $34.0 \mu \mathrm{s}\left({ }^{43} \mathrm{Ca}\right.$ ) was applied, and $180^{\circ}$ pulses of $17.2 \mu$ s were applied on the ${ }^{31} \mathrm{P}$ channel. The recycle delay was set to $4.0 \mathrm{~s}$, the ${ }^{1} \mathrm{H} 90^{\circ}$ (before cross polarization) to $4.0 \mu \mathrm{s}$ and the cross polarization 
contact time to $2 \mathrm{~ms}$. For decoupling, $7.8 \mu \mathrm{s}{ }^{1} \mathrm{H}$ pulses were used (spinal-64 high power decoupling). The number of scans was 16 for $10,20,40$, and 60 recoupling loops. For *OCP (studied at $14 \mathrm{kHz}$ MAS), a $180^{\circ}$ pulse of $34.0 \mu \mathrm{s}\left({ }^{43} \mathrm{Ca}\right.$ ) was applied, and $180^{\circ}$ pulses of $17.2 \mu \mathrm{s}$ were applied on the ${ }^{31} \mathrm{P}$ channel. The recycle delay was set to $4.0 \mathrm{~s}$ and the cross polarization contact time to $2 \mathrm{~ms}$. For decouling, $7.8 \mu \mathrm{s}^{1} \mathrm{H}$ pulses were used (spinal-64 high power decoupling). The number of scans was 16 for 20 recoupling loops.

\section{3. ${ }^{43}$ Computational modeling and GIPAW-DFT calculations.}

${ }^{43}$ Ca NMR parameters were calculated within Kohn-Sham DFT using the QUANTUM-ESPRESSO $\operatorname{code}^{35}$ based on the GIPAW method ${ }^{36}$. Calculations were performed on previously published ${ }^{26}$ geometry-optimized structural models of OCP and OCP-citrate, in which a singly protonated (models A and B) or a non-protonated (model C) citrate anion replaces a hydrogen phosphate site, without performing any further geometry relaxation. The PBE generalised gradient approximation $^{37}$ was used and the valence electrons were described by norm conserving pseudopotentials ${ }^{38}$ in the Kleinman-Bylander ${ }^{39}$ form. The wave functions are expanded on a plane wave basis set with a kinetic energy cut-off of 80 Ry. The integral over the first Brillouin zone is performed using a Monkhorst-Pack $1 \times 2 \times 2$ k-point grid. The principal components $V_{x x}$, $V_{y y}$, and $V_{z z}$ of the EFG tensor defined with $\left|V_{z z}\right| \geq\left|V_{x x}\right| \geq\left|V_{y y}\right|$ are obtained by diagonalization of the tensor. The quadrupolar interaction can then be characterized by the quadrupolar coupling constant $C_{Q}$ and the asymmetry parameter $\eta_{Q}$, which are defined as $C_{Q}=e Q V_{z z} / h$ and $\eta_{\mathrm{Q}}=\left(V_{\mathrm{yy}}-\mathrm{V}_{\mathrm{xx}}\right) / \mathrm{V}_{\mathrm{zz}}$. The experimental value of the quadrupole moment of ${ }^{43} \mathrm{Ca}$ $\left(\mathrm{Q}=-40.8 \times 10^{-30} \mathrm{~m}^{2}\right.$, see Table 1$)$ was used to calculate $C_{Q}$. Absolute shielding tensors are obtained. To fix the ${ }^{43} \mathrm{Ca}$ scale, calculated $\delta_{\text {iso }}$ for a series of reference compounds were 
compared to experimental values ${ }^{17,40}$ so that the average sum of experimental and calculated shifts coincide.

\section{RESULTS and DISCUSSION}

\section{$3.1{ }^{43} \mathrm{Ca} N M R$ of $O C P$}

We begin with a detailed study of the OCP phase. In Figure $2 \mathrm{a}$, the ${ }^{43} \mathrm{Ca}$ MAS spectrum of OCP at very high magnetic field $(20.0 \mathrm{~T})$ is presented. In natural abundance, it is possible to obtain a spectrum of reasonable quality (revealing discontinuities in the overall lineshape) using a $7 \mathrm{~mm}$ rotor in $\sim 20$ hours.
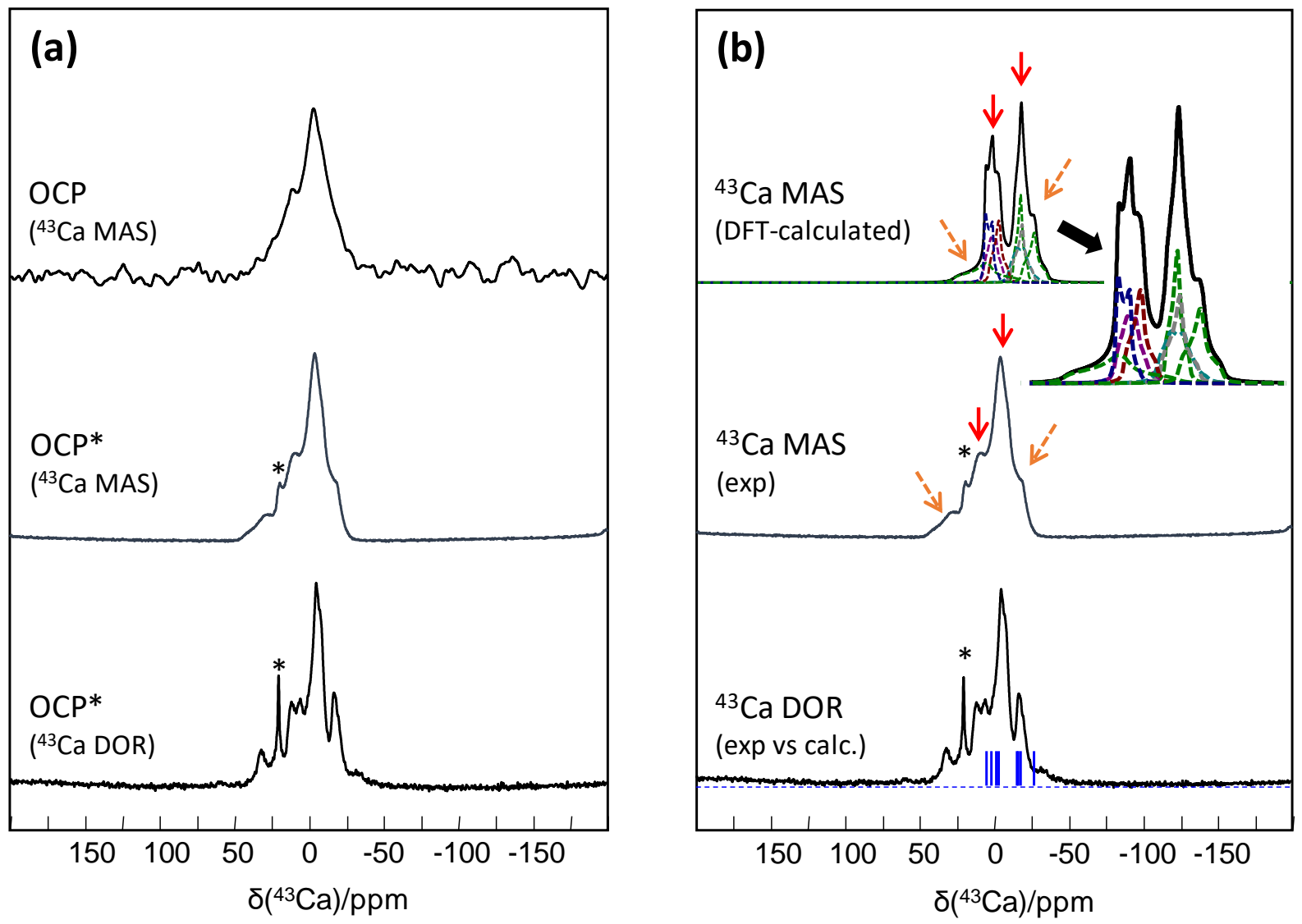

Figure 2. (a) OCP ${ }^{43} \mathrm{Ca}$ MAS and DOR spectra for natural abundance and enriched samples $\left({ }^{*}\right)$ at 20.0 T. The DOR spectrum was recorded for *OCP only. The "•" symbol corresponds to a 
${ }^{*} \mathrm{CaCO}_{3}$ impurity $\left(\delta_{\text {iso. }}\left({ }^{43} \mathrm{Ca}\right)=22.0 \mathrm{ppm}, \mathrm{C}_{\mathrm{Q}}\left({ }^{43} \mathrm{Ca}\right)=1.40 \mathrm{MHz}, \eta_{\mathrm{Q}}=0.0\right) .{ }^{17}$ (b) DFT-calculated (top) and experimental (middle) MAS NMR spectra for *OCP. Insert: zoom of the DFT-calculated contributions. The DOR spectrum $(20.0 \mathrm{~T})$ and calculated $\delta_{\text {iso. }}\left({ }^{43} \mathrm{Ca}\right)$ values (represented as blue bars) shifted by the second-order interaction for the eight calcium sites are presented as well (bottom). Solid red arrows: spectral maxima and orange dashed arrows: shoulders.

According to the OCP crystal structure, the spectrum obtained should correspond to the superposition of eight ${ }^{43} \mathrm{Ca}$ central transitions potentially broadened by quadrupolar second-order effects (not completely averaged by MAS even at $20.0 \mathrm{~T}$ ). Isotopic enrichment in ${ }^{43} \mathrm{Ca}$ brings a considerable gain in terms of signal-to-noise ratio: in 10 minutes a spectrum with minimal noise is obtained. In the case of ${ }^{*} \mathrm{OCP}$, an impurity corresponding to ${ }^{43} \mathrm{Ca}$ labeled calcium carbonate is detected as a very sharp feature ("•" in Figure 2). The very high signal to noise ratio of this spectrum makes it possible to envisage DOR and multinuclear correlation experiments. DOR is an efficient 1D technique capable of fully averaging the second-order quadrupolar effect, by involving two macroscopic reorientation angles of the sample. ${ }^{43} \mathrm{Ca}$ DOR data were rarely reported in the literature. This is mainly due to the inherent complexity of DOR probes making them still specialist equipment. ${ }^{41}$ To the best of our knowledge, three contributions were published in the last years including the spectroscopic characterization of monoclinic hydroxyapatite and $\alpha$-TCP (tetra-calcium phosphate) phases, ${ }^{42}$ the vaterite polymorph of $\mathrm{CaCO}_{3}{ }^{43}$ and $\mathrm{Ca}(\mathrm{OAc})_{2} \cdot 0.5 \mathrm{H}_{2} \mathrm{O} \cdot{ }^{13}$ In the last case, the three calcium resonances were clearly evidenced. Although the rotation frequencies of the two rotors are limited (see section 2.2), it should be possible to efficiently distinguish the isotropic resonances, shifted by a quadrupolar isotropic shift (which depends explicitly on $C_{Q}$ and $\eta_{Q}$, mostly on $C_{Q}$ ) (Figure $2 b$ ). 
The gain in resolution is spectacular between the MAS and the DOR spectra (see Figure 2) although the obtained resolution in the DOR spectrum is still not sufficient to fully resolve all eight isotropic ${ }^{43} \mathrm{Ca}$ contributions.

As mentioned above, the high isotope enrichment allows the implementation of heteronuclear correlation experiments on OCP. The ${ }^{43} \mathrm{Ca}\left\{{ }^{1} \mathrm{H}\right\}$ REDOR experiment allows relative $\mathrm{Ca} . . . \mathrm{H}$ distances to be estimated. As only weak ${ }^{43} \mathrm{Ca}\left\{{ }^{1} \mathrm{H}\right\}$ REDOR dephasing is expected (the heteronuclear ${ }^{43} \mathrm{Ca}-{ }^{1} \mathrm{H}$ dipolar couplings are intrinsically small due to small $\gamma\left({ }^{43} \mathrm{Ca}\right)$ ), the experiment was first tested using *HAp enriched in ${ }^{43} \mathrm{Ca}$ (Figure S2). The observed dephasing is in full agreement with data already published in the literature. ${ }^{44}$ The same experiment was then performed on ${ }^{*} \mathrm{OCP}$ (Figure 3). The dephasing in Figure 3 observed for $24 \mathrm{t}_{\mathrm{R}}$ recoupling cycles is reproducible despite the weakness of the ${ }^{43} \mathrm{Ca}-{ }^{1} \mathrm{H}$ dipolar coupling. Interestingly, the dephasing occurs essentially around the center of the overall lineshape and not at the most shielded and deshielded shoulders of the lineshape. 


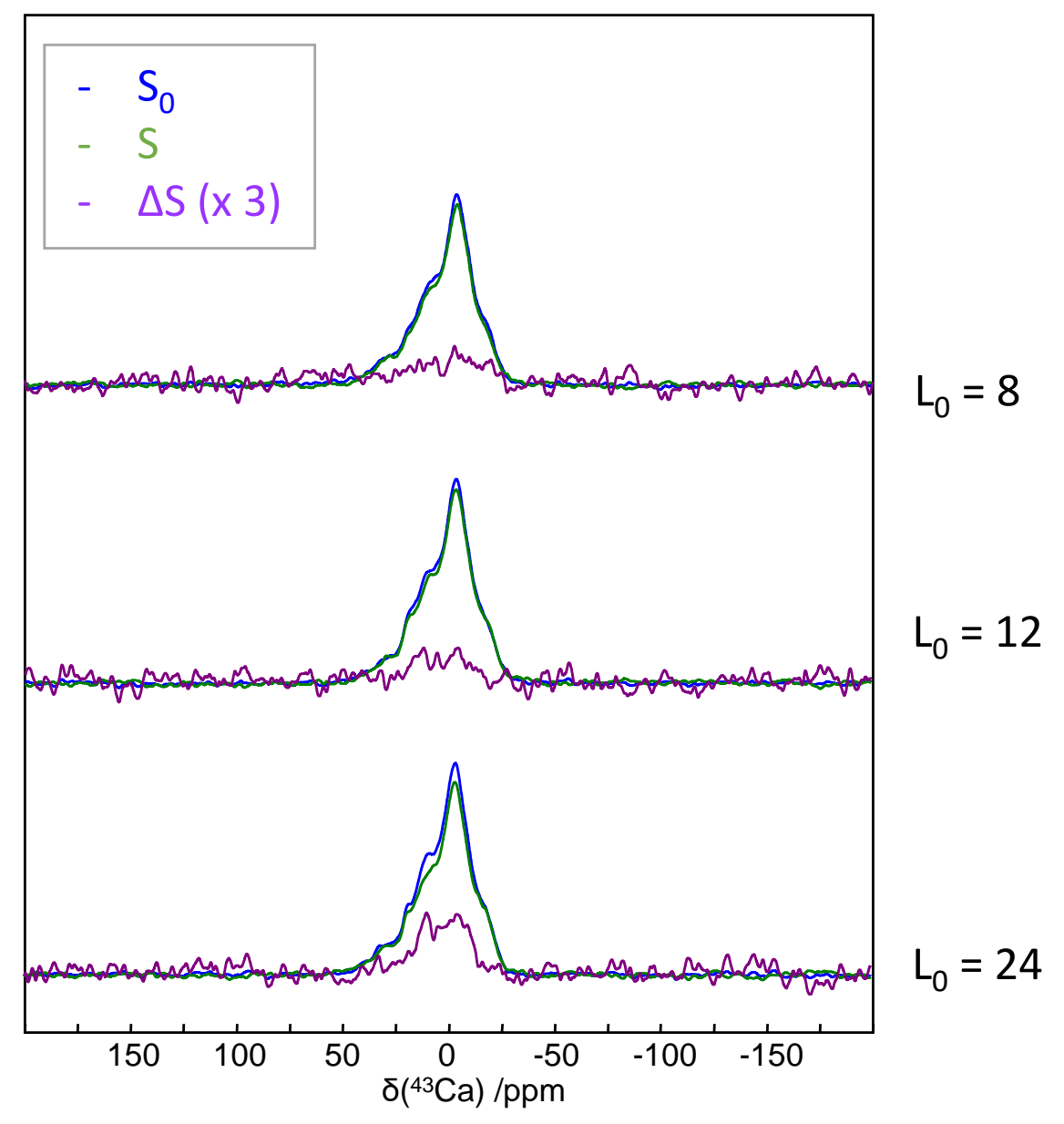

Figure 3. ${ }^{43} \mathrm{Ca}\left\{{ }^{1} \mathrm{H}\right\}$ REDOR experiment results for ${ }^{*} \mathrm{OCP}(20.0 \mathrm{~T}, 14 \mathrm{kHz} \mathrm{MAS})$. Blue spectrum $\left(S_{0}\right)$ : echo (with echo delays increasing from top to bottom), green spectrum (S): REDOR dephased echo for the corresponding recoupling cycles, $L_{0}$, purple spectrum $(\Delta S)$ : difference spectrum ("So-S", multiplied here by 3 to highlight better which parts of the spectrum dephase most).

Looking at the Ca...H distances in the structural model of OCP (Table S2), the eight calcium sites are clearly distinguished by their shortest $\mathrm{Ca}$... $\mathrm{H}$ distance (all $\mathrm{H}$ belonging to water molecules except in the case of $\mathrm{Ca}$ 1, where the closest $\mathrm{H}$ belongs to an $\mathrm{HPO}_{4}{ }^{2-}$ anion): 2.7-2.9 ̊̊ for Ca5, Ca7, Ca9, Ca13, 3.2-3.5 ̊̊ for Ca11, Ca15 and 5.1-5.4 Å for Ca1, Ca3. It 
follows that $\mathrm{Ca}$, Ca7, Ca9, Ca13 contributions should dephase more efficiently using the ${ }^{43} \mathrm{Ca}\left\{{ }^{1} \mathrm{H}\right\}$ REDOR experiment, in the absence of any water molecular motion. It is worth mentioning here that the shortest Ca...H distance in HAp is $\sim 2.7 \AA$, which is close to the shortest Ca...H distances in OCP. However, when comparing the ${ }^{43} \mathrm{Ca}\left\{{ }^{1} \mathrm{H}\right\}$ REDOR data of both phases (Figures 3 and S2), the observed dephasing is much more pronounced for HAp than for OCP. This clearly indicates a drastic reduction of the heteronuclear ${ }^{43} \mathrm{Ca}-{ }^{1} \mathrm{H}$ dipolar couplings for the closest $\mathrm{Ca}$.... H sites in OCP, which is likely to be due to local dynamics of water molecules at room temperature. ${ }^{31}$ This point has not been further investigated here.

It is obvious that MAS alone does not allow observation of resolved isotropic ${ }^{43} \mathrm{Ca}$ signals for OCP individually, and that they cannot be identified using the DOR sequence alone. Unfortunately, it was not possible to combine REDOR and DOR for technical reasons (essentially the power on the ${ }^{1} \mathrm{H}$ channel of the double channels DOR probe was far too low). Given that differences in Ca...P distances are also expected for the different sites in OCP (Table S2), we looked into trying to implement NMR experiments allowing to probe ${ }^{43} \mathrm{Ca}-{ }^{31} \mathrm{P}$ spin pair (which had not yet been analyzed by NMR). Here, as a first attempt for such heteronuclear correlations, we implemented the ${ }^{31} \mathrm{P}\left\{{ }^{43} \mathrm{Ca}\right\} \mathrm{CP}$ REAPDOR sequence with ${ }^{31} \mathrm{P}$ detection (Figure S1). Again, *HAp was used as a model compound to check the progressive dephasing of the ${ }^{31} \mathrm{P}$ signal with increasing dipolar recoupling time. For $60 \mathrm{t}_{\mathrm{R}}$ recoupling cycles, the dephasing of the ${ }^{31} \mathrm{P}$ signal is almost complete (Figure S3). These tests demonstrated that the ${ }^{31} \mathrm{P}\left\{{ }^{43} \mathrm{Ca}\right\} \mathrm{CP}$ REAPDOR sequence can in principle be used to estimate relative ${ }^{43} \mathrm{Ca}-{ }^{31} \mathrm{P}$ heteronuclear dipolar couplings in calcium phosphate phases. In the case of ${ }^{*} \mathrm{OCP}$, the dephasing of the most shielded ${ }^{31} \mathrm{P}$ resonances (centered at $\sim 0.0 \mathrm{ppm}$ ) is slightly less pronounced than for the other resonances (Figure S4). Following the assignments made by Li et al., the ${ }^{31} \mathrm{P}$ signals around $0.0 \mathrm{ppm}$ corresponds to P3, P5 and P6 resonances. ${ }^{27}$ In Table 
S3, it is shown that the minimum P...Ca distance is roughly $3.1 \AA$ for all six phosphorus sites, but that the number of the closest calcium neighbors $(<4 \AA)$ is much reduced for P5 and P6. This explains the reduced dephasing in the ${ }^{31} \mathrm{P}\left\{{ }^{43} \mathrm{Ca}\right\} \mathrm{CP}$ REAPDOR experiment, and demonstrate the efficiency of this sequence for distinguishing ${ }^{31} \mathrm{P}$ sites on the basis of their relative ${ }^{43} \mathrm{Ca}$ proximities. Future developments will involve the "reverse" study, by using ${ }^{43} \mathrm{Ca}$ detection instead, to try to help differentiate the Ca sites depending on their closest $\mathrm{P}$ neighbors.

At this stage, although the ${ }^{43} \mathrm{Ca}\left\{{ }^{1} \mathrm{H}\right\}$ REDOR experiments provide some clues as to which ${ }^{43} \mathrm{Ca}$ resonances correspond to $\mathrm{Ca}$ sites closer to $\mathrm{H}$, in order to go further in the assignment of the individual resonances of OCP, it is necessary to use first principles GIPAW calculations to estimate the NMR parameters of each calcium site $\left(\delta_{\text {iso., }} \mathrm{C}_{\mathrm{Q}}\right.$ and $\left.\eta_{\mathrm{Q}}\right)$. The calculated parameters are presented in Table 2 and are used for the simulation of the OCP MAS spectrum in Figure $2 b$, top. Actually, 16 sets of data corresponding to 8 duplicates are presented for OCP as a doubled cell was used in the more general case of OCP-citrate structures (see section 2.3). The agreement between the experimental and calculated data is fairly good. Indeed, the main features (spectral maxima, i.e. red arrows, and shoulders, i.e. orange dashed arrows) of the overall lineshape are correctly reproduced by the calculations (Figure $2 b$, comparison of top and medium spectra). We then used the first principles calculated data to estimate second-order quadrupolar isotropic shifts. These are represented below the DOR spectrum in Figure $2 b$. One observes a global underestimation of the computed shifts (see below). 
Interestingly, we note a large variation of $\delta_{\text {iso. }}\left({ }^{43} \mathrm{Ca}\right.$ ) in OCP (over about $50 \mathrm{ppm}$ which corresponds to $\sim 20 \%$ of the total ${ }^{43} \mathrm{Ca}$ chemical shift range.${ }^{17}$ In a number of previous studies, $\delta_{\text {iso. }}\left({ }^{43} \mathrm{Ca}\right)$ can be related to a certain extent to the average of the $\mathrm{Ca}-\mathrm{O}$ distances in the first coordination sphere of calcium. ${ }^{17}$ In Figure S5 (red dots), the average Ca-O distances for each of the eight calcium sites of pure OCP have been plotted as a function of the calculated $\delta_{\text {iso. }}\left({ }^{43} \mathrm{Ca}\right)$ for two different cut-offs (corresponding to maximum Ca-O distances of 2.7 and $2.9 \AA$ A. In both cases, the data are scattered and no clear trend can be established, possibly because of the large diversity in Ca local environment (the oxygen atoms linked to $\mathrm{Ca}^{2+}{ }^{2}$ coming from water, phosphate and/or hydrogen-phosphate ligands). However, one notes that three groups of ${ }^{43} \mathrm{Ca}$ isotropic chemical shifts can be highlighted (above $20 \mathrm{ppm}$, between 0 and $10 \mathrm{ppm}$, and below $0 \mathrm{ppm})$ and that the most deshielded value (27.7 ppm) corresponds indeed to the shortest average Ca-O distance (when considering a cut-off of $2.7 \AA ̊$ ).

The three groups of ${ }^{43} \mathrm{Ca}$ isotropic chemical shifts are clear, corresponding to: $\mathrm{Ca} 11$, (Ca3, Ca9, Ca13) and (Ca1, Ca5, Ca7, Ca15), in decreasing order of $\delta_{\text {iso. }}\left({ }^{43} \mathrm{Ca}\right)$. These groups are compatible with the overall lineshape of the ${ }^{43} \mathrm{Ca}$ MAS spectrum (Figure $2 b$ ), the most extreme chemical shifts (Ca11, Ca15) contributing to shoulders (dashed orange arrows). However, the calculated ${ }^{43} \mathrm{Ca}$ isotropic chemical shift values are globally underestimated when compared to the experimental ones. This is also observed when looking at the calculated isotropic values in the DOR spectrum (Figure 2b, blue solid lines). Most importantly, Ca5, Ca7, Ca9 and Ca13 contributions are centered in the middle of the lineshape, in agreement with the dephasing observed in the ${ }^{43} \mathrm{Ca}\left\{{ }^{1} \mathrm{H}\right\}$ REDOR experiments (Figure 3 ). A contrario, the most extreme contributions are not dephased in REDOR, as expected from the long Ca...H distances involving Ca11 and Ca15 (Table S2). 
Thus our initial summary is that ${ }^{43} \mathrm{Ca}$ MAS NMR is a suitable tool of investigation for the structural analysis of complex hydrated calcium phosphate such as OCP. Unfortunately, the DOR resolution was not sufficient to completely resolve signals from the eight calcium sites and to allow definite assignments by combining experimental and GIPAW computed data. Nevertheless, we can conclude that there are three groups of ${ }^{43} \mathrm{Ca}$ chemical shifts in $\mathrm{OCP}$ and that Ca11 and Ca15 correspond to the most deshielded and shielded sites, respectively. More generally, this study demonstrates that ${ }^{43} \mathrm{Ca}$ NMR is a very sensitive spectroscopy to study local environment in OCP, which prompted us to apply the technique to hybrid derivatives, as detailed below.

\section{$3.2{ }^{43} \mathrm{Ca}$ NMR of intercalated OCP hybrids}

We then studied the interaction of selected metabolic acids in OCP leading to intercalated OCP hybrids. Figure 4 demonstrates that natural abundance ${ }^{43} \mathrm{Ca}$ MAS NMR spectroscopy is suitable for the direct comparison of various intercalated OCP phases involving citrate, formate, adipate, and succinate molecules, as well as a mixed citrate/formate phase. The ${ }^{43} \mathrm{Ca}$ spectra for the citrate, formate and citrate/formate are quite comparable. On the other hand, quite different ${ }^{43} \mathrm{Ca}$ spectra are obtained for the succinate and adipate hybrids, for which the

${ }^{43} \mathrm{Ca}$ lineshape is somewhat sharper. It is interesting to note that these two bis-carboxylates (succinate and adipate) lead to similar ${ }^{43} \mathrm{Ca}$ signatures, suggesting a similar mode of intercalation of the molecules in the hydrated layer. We tentatively ascribe these structural differences to the length and symmetry of the organic chains in the various metabolic acids (Figure 4). Succinate and adipate are capable of being incorporated into the OCP structure in a manner that retains the unit cell center of symmetry, whereas the symmetry of formate and citrate makes this impossible for these anions. Thus the succinate and adipate hybrids can in 
principle retain much of the original OCP crystalline structure whereas the formate and citrate hybrids cannot. ${ }^{27}$

In order to try to further interpret the ${ }^{43} \mathrm{Ca}$ MAS NMR spectra of these hybrids, and to account for the difference observed in comparison to pure OCP, a more extensive modeling study (at the DFT level) was performed for OCP-citrate. ${ }^{26}$

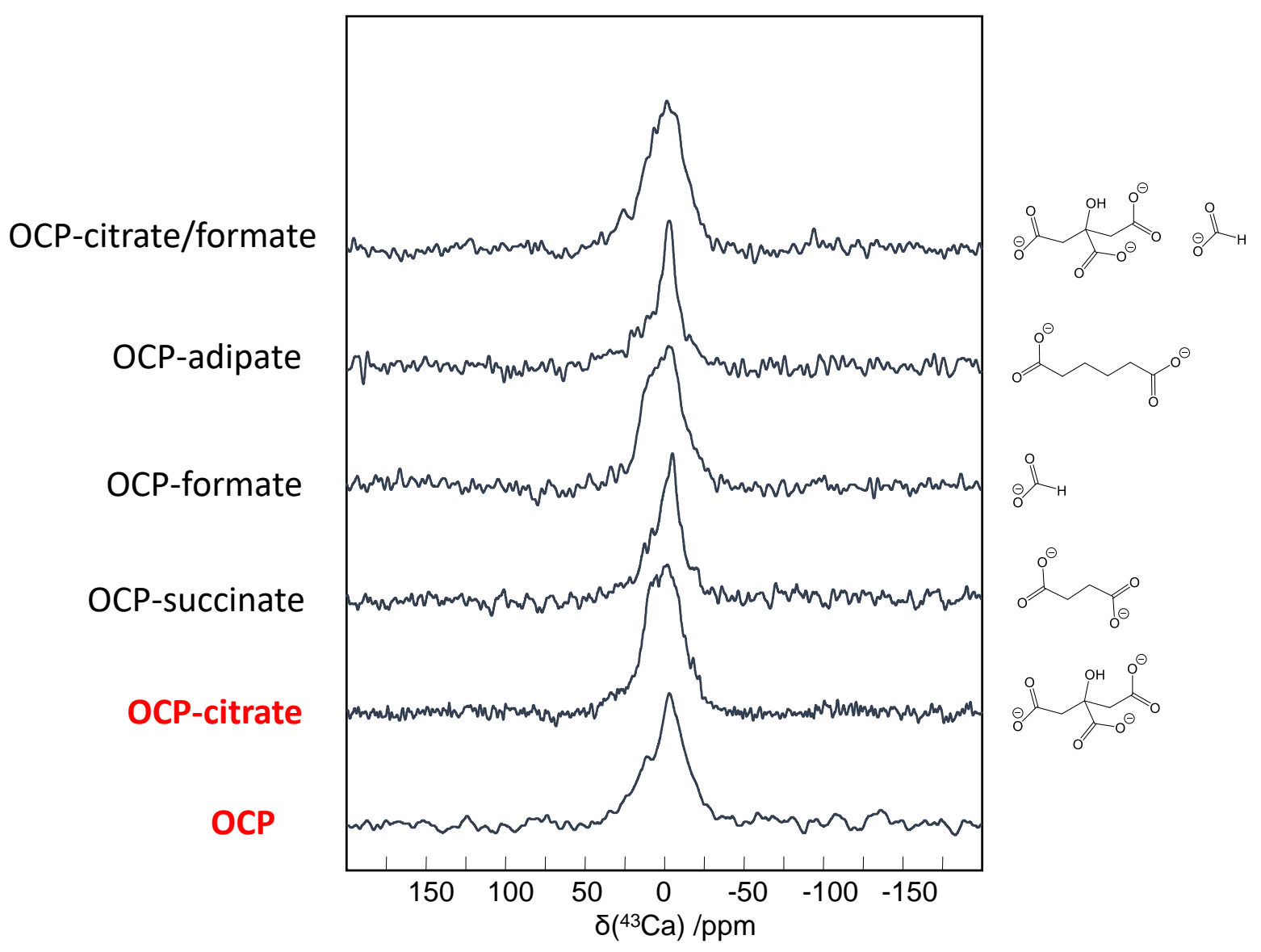

Figure $4 .{ }^{43} \mathrm{Ca}$ natural abundance MAS NMR spectra of hydrid OCP phases involving metabolic acids (from top to bottom: mixed OCP-citrate/formate, adipate, formate, succinate, and citrate). The ${ }^{43} \mathrm{Ca}$ MAS NMR spectrum of OCP is also presented for comparison (natural abundance as well).

\section{$3.3{ }^{43} \mathrm{Ca}$ NMR crystallography of OCP-citrate}


The NMR crystallography approach was applied to the hybrid OCP-citrate derivative. The ${ }^{43} \mathrm{Ca}$ NMR modeling study was performed on five DFT relaxed models resulting from the partial exchange of $\mathrm{HPO}_{4}{ }^{2-}$ groups by citrates in the hydrated layer of OCP (Figure 1), each of these models having been previously described in the literature. ${ }^{26}$ Three different incorporation modes were tested for citrates. Models A and B correspond to protonated citrate molecules (HCIT) whereas model C corresponds to non-protonated citrate molecules (CIT). Adding 1 water molecule to models $A$ and $B$ leads to models $\mathrm{A}+\mathrm{H}_{2} \mathrm{O}$ and $\mathrm{B}+\mathrm{H}_{2} \mathrm{O}$ (Figure 5 ). 

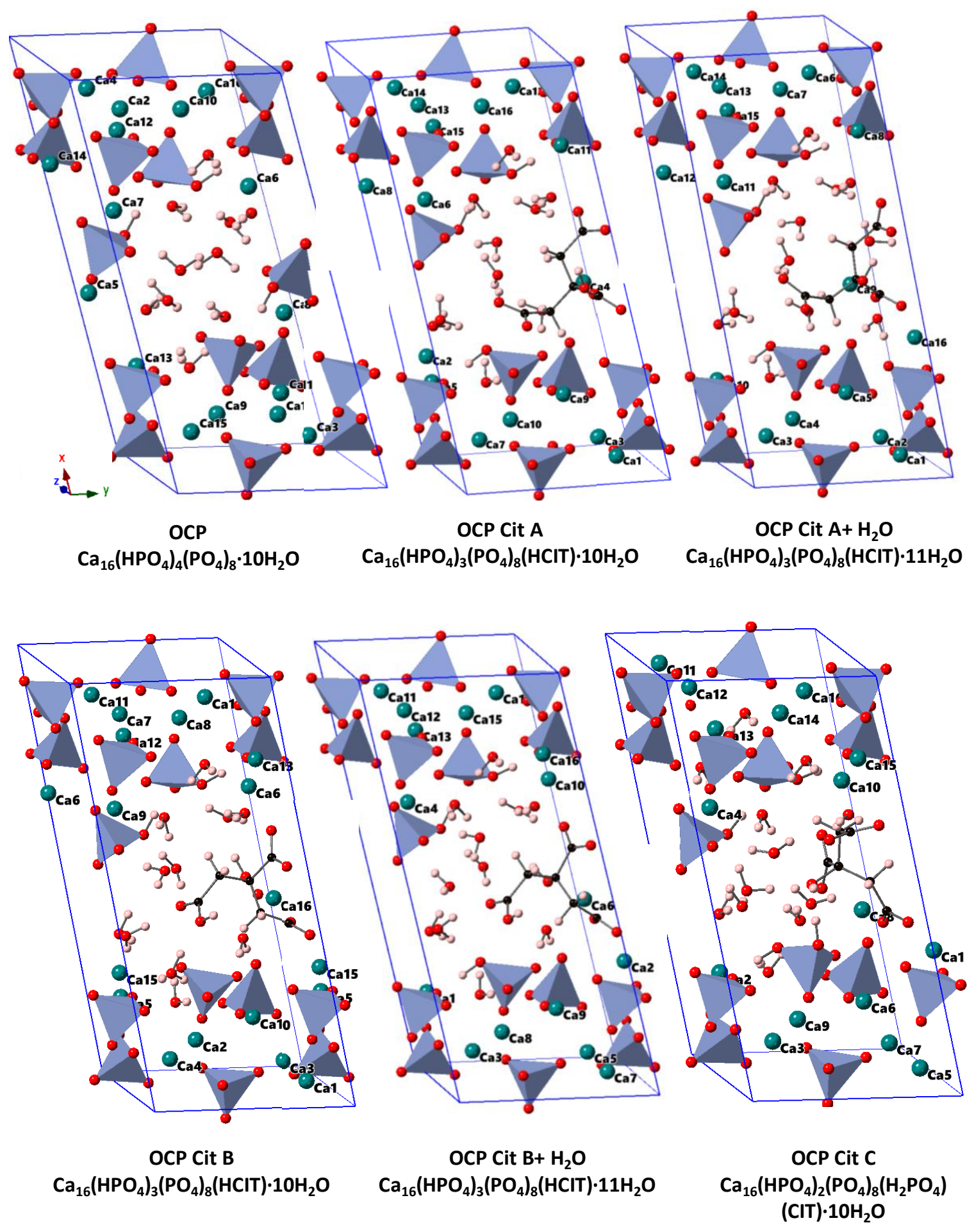

Figure 5. DFT relaxed OCP and OCP-citrate models. ${ }^{26} \mathrm{C}$ : black, $\mathrm{H}$ : light pink, Ca: green, O: red, $\mathrm{PO}_{4}{ }^{3}$ : blue tetrahedra. The citrate molecules exchange some of the $\mathrm{HPO}_{4}{ }^{2-}$ groups in the hydrated layer of OCP. HCIT: protonated citrate molecule (models A and B), CIT: nonprotonated citrate molecule (model C). Adding one water molecule leads to models $\mathrm{A}+\mathrm{H}_{2} \mathrm{O}$ and $\mathrm{B}+\mathrm{H}_{2} \mathrm{O}$, respectively. 


\begin{tabular}{|c|c|c|c|c|c|c|c|c|c|}
\hline & \multicolumn{3}{|c|}{$\begin{array}{c}\mathrm{OCP} \\
\mathrm{Ca}_{16}\left(\mathrm{HPO}_{4}\right)_{4}\left(\mathrm{PO}_{4}\right)_{8} \cdot 10 \mathrm{H}_{2} \mathrm{O}\end{array}$} & \multicolumn{3}{|c|}{$\begin{array}{c}\text { OCP Cit A } \\
\mathrm{Ca}_{16}\left(\mathrm{HPO}_{4}\right)_{3}\left(\mathrm{PO}_{4}\right)_{8}(\mathrm{HCIT}) \cdot 10 \mathrm{H}_{2} \mathrm{O}\end{array}$} & \multicolumn{3}{|c|}{$\begin{array}{c}\text { OCP Cit A+ } \mathrm{H}_{2} \mathrm{O} \\
\mathrm{Ca}_{16}\left(\mathrm{HPO}_{4}\right)_{3}\left(\mathrm{PO}_{4}\right)_{8}(\mathrm{HClT}) \cdot 11 \mathrm{H}_{2} \mathrm{O}\end{array}$} \\
\hline & $\begin{array}{c}\delta_{\text {iso }} \\
(\mathrm{ppm})\end{array}$ & $\mathrm{C}_{\mathrm{Q}}(\mathrm{MHz})$ & $\eta_{\mathrm{Q}}$ & $\begin{array}{c}\delta_{\text {iso }} \\
(\mathrm{ppm})\end{array}$ & $\mathrm{C}_{\mathrm{Q}}(\mathrm{MHz})$ & $\eta_{Q}$ & $\begin{array}{c}\delta_{\text {iso }} \\
(\mathrm{ppm})\end{array}$ & $\mathrm{C}_{\mathrm{Q}}(\mathrm{MHz})$ & $\eta_{Q}$ \\
\hline Ca1 & -12.6 & -2.15 & 0.89 & -9.4 & 2.24 & 0.89 & -7.6 & 2.13 & 0.87 \\
\hline $\mathrm{Ca} 2$ & -12.6 & -2.15 & 0.89 & 5.7 & -2.76 & 0.17 & 1.6 & 2.81 & 0.63 \\
\hline Ca3 & 7.8 & 2.84 & 0.52 & 6.3 & 2.72 & 0.66 & -14.2 & -3.20 & 0.50 \\
\hline $\mathrm{Ca} 4$ & 7.8 & 2.84 & 0.52 & -8.2 & -6.72 & 0.75 & -12.6 & 2.69 & 0.53 \\
\hline Ca5 & -8.7 & -3.24 & 0.47 & 7.0 & 3.41 & 0.47 & 20.9 & 2.54 & 0.25 \\
\hline Ca6 & -8.7 & -3.24 & 0.47 & -3.0 & 2.01 & 0.19 & -8.8 & -3.81 & 0.58 \\
\hline $\mathrm{Ca} 7$ & -11.0 & -2.63 & 0.94 & -14.2 & -3.26 & 0.54 & -1.6 & -2.50 & 0.50 \\
\hline Ca8 & -11.0 & -2.63 & 0.94 & 0.7 & 2.06 & 0.57 & 0.8 & -2.13 & 0.44 \\
\hline Ca9 & 3.8 & -2.53 & 0.85 & 23.8 & 3.58 & 0.30 & 39.2 & -3.91 & 0.99 \\
\hline Ca10 & 3.8 & -2.53 & 0.85 & -6.6 & 2.94 & 0.31 & 5.1 & 3.36 & 0.46 \\
\hline Ca11 & 27.7 & -4.58 & 0.89 & 7.5 & -2.32 & 0.25 & -1.3 & 2.98 & 0.32 \\
\hline Ca12 & 27.7 & -4.58 & 0.89 & -12.3 & -3.24 & 0.91 & -3.6 & 1.91 & 0.87 \\
\hline Ca13 & 8.2 & -2.40 & 0.05 & -3.3 & -2.37 & 1.00 & -9.8 & -2.35 & 0.95 \\
\hline Ca14 & 8.2 & -2.40 & 0.05 & 0.4 & 3.05 & 0.27 & 0.8 & 2.86 & 0.26 \\
\hline Ca15 & -18.2 & -2.84 & 0.89 & 21.1 & 3.94 & 0.79 & 25.0 & -4.60 & 0.87 \\
\hline \multirow[t]{2}{*}{ Ca16 } & -18.2 & -2.84 & 0.89 & 1.0 & -2.74 & 0.67 & 1.5 & 2.41 & 0.53 \\
\hline & \multicolumn{3}{|c|}{$\begin{array}{c}\text { OCP Cit B } \\
\mathrm{Ca}_{16}\left(\mathrm{HPO}_{4}\right)_{3}\left(\mathrm{PO}_{4}\right)_{8}(\mathrm{HCIT}) \cdot 10 \mathrm{H}_{2} \mathrm{O}\end{array}$} & \multicolumn{3}{|c|}{$\begin{array}{c}\text { OCP Cit B+ } \mathrm{H}_{2} \mathrm{O} \\
\mathrm{Ca}_{16}\left(\mathrm{HPO}_{4}\right)_{3}\left(\mathrm{PO}_{4}\right)_{8}(\mathrm{HClT}) \cdot 11 \mathrm{H}_{2} \mathrm{O}\end{array}$} & \multicolumn{3}{|c|}{$\begin{array}{c}\text { OCP Cit C } \\
\mathrm{Ca}_{16}\left(\mathrm{HPO}_{4}\right)_{2}\left(\mathrm{PO}_{4}\right)_{8}\left(\mathrm{H}_{2} \mathrm{PO}_{4}\right)(\mathrm{CIT}) \cdot 10 \mathrm{H}_{2} \mathrm{O}\end{array}$} \\
\hline Ca1 & -5.7 & 2.34 & 0.64 & -0.6 & 3.95 & 0.56 & 38.5 & 1.87 & 0.72 \\
\hline $\mathrm{Ca} 2$ & -3.5 & 3.08 & 0.31 & 24.9 & 1.42 & 0.22 & -3.6 & 2.29 & 0.67 \\
\hline Ca3 & 1.1 & 2.39 & 0.69 & -13.5 & -3.33 & 0.24 & -19.2 & -3.06 & 0.51 \\
\hline Ca4 & -10.3 & -3.29 & 0.46 & -2.3 & 1.73 & 0.80 & 11.2 & 3.06 & 0.25 \\
\hline Ca5 & -6.9 & 3.77 & 0.73 & 0.2 & 2.46 & 0.43 & -7.7 & 2.33 & 0.53 \\
\hline Ca6 & 9.4 & -2.88 & 0.06 & -6.3 & -6.46 & 0.40 & 27.3 & 4.53 & 0.75 \\
\hline $\mathrm{Ca} 7$ & -3.6 & 2.39 & 0.86 & -6.8 & 2.38 & 0.68 & -6.0 & 2.91 & 0.57 \\
\hline Ca8 & -2.8 & 2.67 & 0.89 & -1.2 & 2.94 & 0.60 & -52.8 & -2.44 & 0.44 \\
\hline Ca9 & 12.6 & -1.88 & 0.99 & 27.8 & 3.18 & 0.11 & -5.2 & 2.62 & 0.81 \\
\hline Ca10 & 34.8 & 2.94 & 0.56 & 3.3 & -2.29 & 0.45 & -1.1 & -2.93 & 0.99 \\
\hline Ca11 & -0.5 & 2.75 & 0.27 & -1.1 & 2.73 & 0.34 & -12.1 & 2.42 & 0.53 \\
\hline Ca12 & 21.8 & 4.46 & 0.51 & -3.6 & 2.50 & 0.80 & -0.4 & 3.04 & 0.71 \\
\hline Ca13 & 6.3 & -2.17 & 0.59 & 19.8 & 4.46 & 0.55 & 20.7 & 4.05 & 0.95 \\
\hline Ca14 & -7.5 & -3.42 & 0.84 & -6.9 & -3.71 & 0.74 & -4.4 & -2.24 & 0.93 \\
\hline Ca15 & 8.2 & 1.96 & 0.38 & 1.4 & -2.81 & 0.76 & -2.9 & 2.56 & 0.92 \\
\hline Ca16 & -3.7 & -6.61 & 0.63 & -0.9 & -2.01 & 0.51 & -19.6 & -3.45 & 0.60 \\
\hline
\end{tabular}

Table 2. GIPAW computed ${ }^{43} \mathrm{Ca}$ NMR parameters for OCP and for five structural models of OCP-citrate in which a singly protonated (A and $B$ ) or a non-protonated $(\mathrm{C})$ citrate anion (CIT) 
replaces a hydrogen phosphate site. Models for OCP-citrate are presented in Figure 5 . In the case of OCP, 16 sets of 8 duplicate values are presented due to the use of a doubled cell.

All OCP-citrate models were used as starting points for GIPAW calculations. The calculated ${ }^{43} \mathrm{Ca}$ NMR parameters are presented in Table 2. The corresponding calculated MAS spectra are presented in Figure 6a.

(a) Calculated spectra
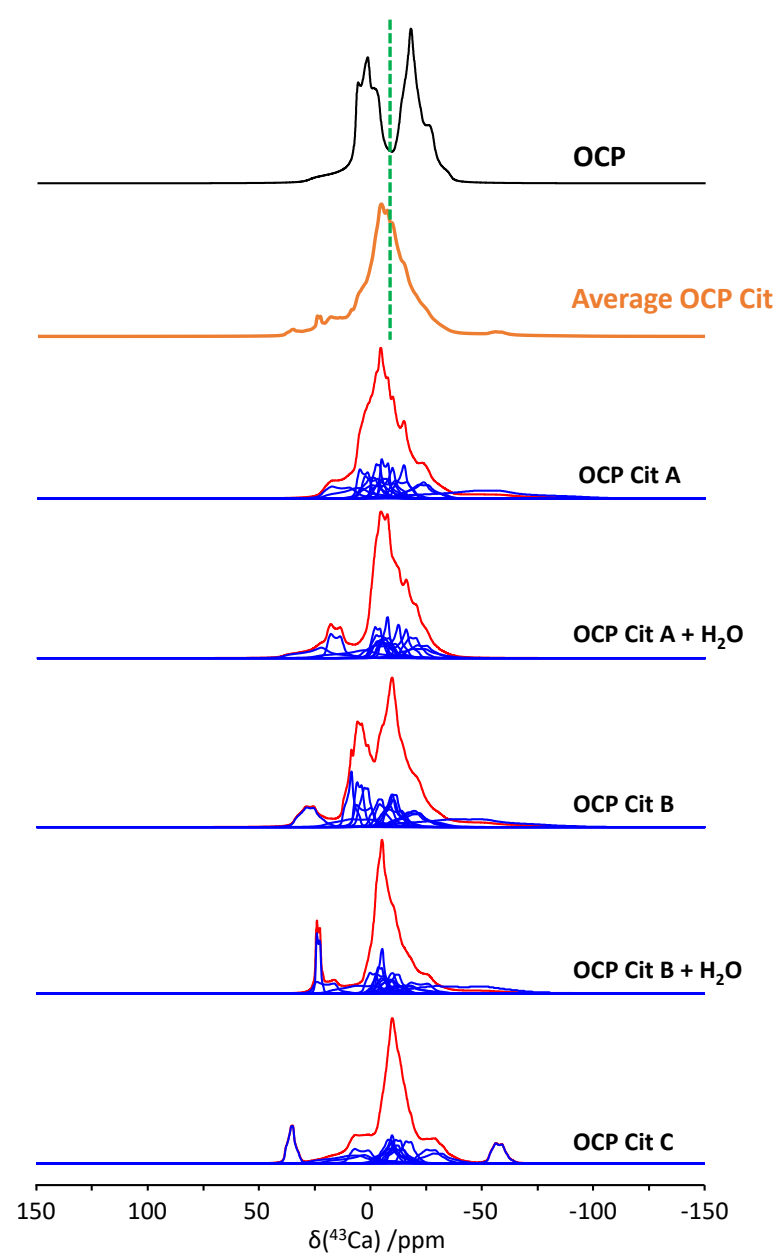

(b) Experimental spectra

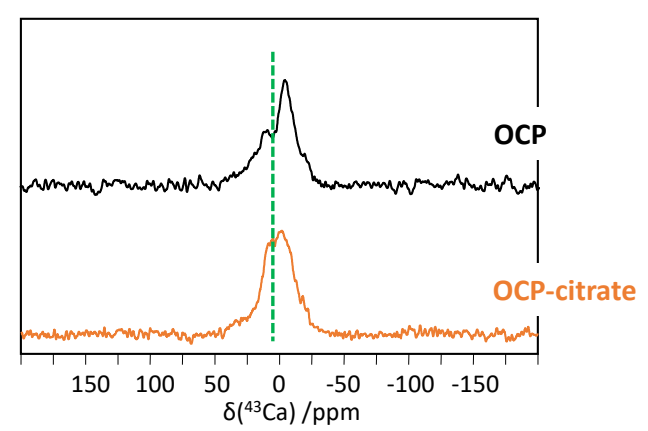

Figure 6. (a) GIPAW calculated ${ }^{43} \mathrm{Ca}$ MAS NMR spectra for all five OCP-citrate models. Average OCP Cit (in orange) corresponds to the average of the 5 spectra. Blue lines: individual ${ }^{43} \mathrm{Ca}$ 
resonances, with the corresponding sum (red lines). Each blue line corresponds to a set of data $\left(\delta_{\text {iso }}\left({ }^{43} \mathrm{Ca}\right), \mathrm{C}_{\mathrm{Q}}, \eta_{\mathrm{Q}}\right)$ given in Table 2 , using the DMFit software ${ }^{45}$ with unit intensity for the associated area. The GIPAW calculated ${ }^{43} \mathrm{Ca}$ MAS spectrum for OCP is shown for comparison (in black). (b) Experimental MAS spectra of OCP (black) and OCP-citrate (orange). The vertical green dashed line is a guide for the eye to highlight the difference in lineshape for OCP and OCP-citrate.

Looking carefully at Table 2 , the vast majority of computed $\delta_{\text {iso }}\left({ }^{43} \mathrm{Ca}\right)$ is restricted in the $25 \mathrm{ppm} /-25 \mathrm{ppm}$ range of chemical shift. However, the corresponding distribution is not identical from one model to the other one. As an example, in the case of OCP Cit B model, two distinct resonances are observed in the sum spectrum - red line, in obvious contradiction with the experimental data (Figure 6b). In the case of the OCP Cit C model, the line width of the central part of the corresponding sum spectrum is underestimated when compared to the experimental data. This demonstrates that a single model is not adequate to describe the OCP derived structure. Given that the "real" mode of intercalation of citrate more likely corresponds to a combination of the five individual models, an average calculated spectrum is presented in Figure 6a (named Average OCP Cit) as well (top orange spectrum). This calculated spectrum shows a particular lineshape which is clearly different from the one calculated for "pure" OCP. Indeed, the spectrum of OCP-citrate is "smoother" around 0.0 ppm with a slightly deshielded shoulder. The differences observed on the experimental spectra for OCP and OCP-citrate are overall similar as those observed for the calculated data. This is highlighted by the green dashed line in Figure $6 \mathrm{~b}$. The left shoulder is clearly associated to a few calcium sites present in all five models, exhibiting deshielded ${ }^{43} \mathrm{Ca}$ isotropic chemical shifts (Table 2). In Figure S6, we have tried to establish a structural correlation between the most 
extreme $\delta_{\text {iso. }}\left({ }^{43} \mathrm{Ca}\right)$ and local environment around the calcium atoms. For a given calcium site, the shortest $\mathrm{Ca}-\mathrm{O}$ distances were extracted with particular emphasis on the chemical nature of the neighboring groups: phosphates/hydrogen-phosphates, citrates, water molecules. Interestingly, all deshielded calcium atoms are 6-fold coordinated exhibiting several short Ca$\mathrm{O}(\sim 2.2-2.3 \AA)$ distances and a large variety of coordinated molecules (citrate, phosphate groups, water). In contrast, the most shielded chemical shifts correspond more to 7-fold coordinated calcium atoms. As mentioned above, the diversity in the coordinated molecules and the variation of the coordination number could explain the lack of correlation between computed $\delta_{\text {iso. }}\left({ }^{43} \mathrm{Ca}\right)$ and average $\mathrm{Ca}-\mathrm{O}$ distances (Figure $\mathrm{S} 5$ ).

We conclude that ${ }^{43} \mathrm{Ca}$ MAS NMR in combination with NMR crystallography remains pertinent for the description and interpretation of subtle structural details observed in the NMR spectra of hybrid intercalated OCP derived. As shown in Figure 4, OCP-adipate and OCP-succinate derivatives were clearly distinguished by their ${ }^{43} \mathrm{Ca}$ MAS NMR spectra suggesting symmetric positions/orientations of the metabolic acids in the hydrated layer of OCP. New DFT models involving adipate and succinate molecules should help us to interpret these spectra in a near future.

\section{CONCLUSIONS}

In this contribution, we have demonstrated that despite unfavorable NMR characteristics of calcium-43 (low $\gamma$ and very low natural abundance), ${ }^{43} \mathrm{Ca}$ NMR spectroscopy is a valuable tool of investigation for complex calcium phosphate phases like OCP derivatives. In particular, we have focused on the detailed interpretation of single and double resonance experiments on OCP in combination with ${ }^{43} \mathrm{Ca}$ NMR crystallography. The experiments presented here included 
the first ${ }^{31} \mathrm{P}\left\{{ }^{43} \mathrm{Ca}\right\}$ CP REAPDOR studies on calcium-phosphate, which could be of interest for future analyses of disordered or amorphous biomaterials. We have also demonstrated that natural abundance ${ }^{43} \mathrm{Ca}$ NMR spectroscopy remains pertinent for intercalated OCP hybrids (notably for discussing the validity of DFT optimized models), and that is thus a valuable tool to include in the study of complex biomaterials and biominerals.

\section{ACKNOWLEDGMENTS}

NMR spectroscopic calculations were performed using HPC resources from GENCI-IDRIS (Grant 097535). YL was funded by a UK EPSRC doctoral training award. The UK $850 \mathrm{MHz}$ solid-state NMR Facility used in this research was funded by EPSRC and BBSRC (contract reference PR140003), as well as the University of Warwick including via part funding through Birmingham Science City Advanced Materials Projects 1 and 2 supported by Advantage West Midlands (AWM) and the European Regional Development Fund (ERDF).

\footnotetext{
${ }^{1}$ P. Pyykkö, Mol. Phys. 2018, 116, 1328.

${ }^{2}$ C. Bonhomme, C. Gervais, N. Folliet, F. Pourpoint, C. Coelho Diogo, J. Lao, E. Jallot, J. Lacroix, J.-M. Nedelec, D. Iuga, J.V. Hanna, M.E. Smith, Y. Xiang, J. Du, D. Laurencin, J. Am. Chem. Soc. 2012, 134, 12611.

3 J. Lacroix, J. Lao, J.-M. Nedelec, E. Jallot, Nucl. Instr. Methods B 2013, 306, 153.

${ }^{4}$ R. Schurko, Acc. Chem. Res. 2013, 46, 1985 and references therein.

${ }^{5}$ D. luga, H. Schäfer, R. Verhagen, A.P.M. Kentgens, J. Magn. Reson. 2000, 147, 192.

${ }^{6}$ M. Goswami, P.J.M. van Bentum, A.P.M. Kentgens, J. Magn. Reson. 2012, 219, 25.

${ }^{7}$ R. Dupree, A.P. Howes, S.C. Kohn, Chem. Phys. Lett. 1997, 276, 399.

${ }^{8}$ C. Bonhomme, X. Wang, I. Hung, Z. Gan, C. Gervais, C. Sassoye, J. Rimsza, J. Du, M.E. Smith, J.V. Hanna,

S. Sarda, P. Gras, C. Combes, D. Laurencin, Chem. Commun. 2018, 54, 9591.

${ }^{9}$ D. Laurencin, M.E. Smith, Prog. Nucl. Magn. Reson. Spectr. 2013, 68, 1.
} 
${ }^{10}$ C.M. Widdifield, Ann. Rep. NMR Spectrosc. 2017, 92, 227.

${ }^{11}$ D. Laurencin, C. Gervais, A. Wong, C. Coelho, F. Mauri, D. Massiot, M.E. Smith, C. Bonhomme, J. Am. Chem. Soc. 2009, 131, 13430.

${ }^{12}$ A. Samoson, E. Lippmaa, A. Pines, Mol. Phys. 1988, 65, 1013.

${ }^{13}$ K.M.N. Burgess, F.A. Perras, I.L. Moudrakovski, Y. Xu, D.L. Bryce, Can. J. Chem. 2015, 93, 799.

${ }^{14}$ A. Wong, P.M. Aguiar, T. Charpentier, D. Sakellariou, Chem. Sci. 2011, 2, 815.

${ }^{15}$ (a) S.T. Holmes, W.D. Wang, G. Hou, C. Dybowski, W. Wang, S. Bai, Phys. Chem. Chem. Phys. 2019, $21,6319$.

(b) S. Bai, C.M. Quinn, S.T. Holmes, C. Dybowski, Magn. Reson. Chem. 2019, special issue, 1.

${ }^{16}$ D.L. Bryce, E.B. Bultz, D. Aebi, J. Am. Chem. Soc. 2008, 130, 9282.

${ }^{17}$ C. Gervais, D. Laurencin, A. Wong, F. Pourpoint, J. Labram, B. Woodward, A.P. Howes, K.J. Pike, R. Dupree, F. Mauri, C. Bonhomme, M.E. Smith, Chem. Phys. Lett. 2008, 464, 42.

${ }^{18}$ S.T. Holmes, S. Bai, R.J. Iuliucci, K.T. Mueller, C. Dybowski, J. Comput. Chem. 2017, 38, 949.

${ }^{19}$ S. Chen, B.E.G. Lucier, M. Chen, V.V. Terskikh, Y. Huang, Chem. Eur. J. 2018, 24, 8732.

${ }^{20}$ S. Chen, B.E.G. Lucier, W. Luo, X. Xie, K. Feng, H. Chan, V.V. Terskikh, X. Sun, T.-K. Sham, M.S. Workentin, Y. Huang, ACS Appl. Mater. \& Interf. 2018, 10, 30296.

${ }^{21}$ A.S. Andreev, N.V. Bulina, M.V. Chaikina, I.Y. Prosanov, V.V. Terskikh, O.B. Lapina, Solid St. Nucl. Magn. Reson. 2017, 84, 151.

${ }^{22}$ A. Wong, A.P. Howes, R. Dupree, M.E. Smith, Chem. Phys. Lett. 2006, 427, 201.

${ }^{23}$ G.M. Bowers, R.J. Kirkpatrick, Cryst. Growth Design 2011, 11, 5188.

${ }^{24}$ H. Colas, L. Bonhomme-Coury, C. Diogo, F. Tielens, F. Babonneau, C. Gervais, D. Bazin, D. Laurencin, M.E. Smith, J.V. Hanna, M. Daudon, C. Bonhomme, CrystEngComm. 2013, 15, 8840.

${ }^{25}$ (a) Y.Y. Hu, A. Rawal, K. Schmidt-Rohr, Proc. Natl. Acad. Sci. USA 2010, 107, 22425. (b) Y. Wang, S. von Euw, F.M. Fernandes, S. Cassaignon, M. Selmane et al., Nature Mater. 2013, 12, 1144.

${ }^{26}$ E. Davies, K.H. Muller, W.C. Wong, C.J. Pickard, D.G. Reid, J.N Skepper, M.J. Duer, Proc. Natl. Acad. Sci. USA 2014, 111, E1354.

${ }^{27}$ Y. Li, D.G. Reid, M.J. Duer, J.C.C. Chan, Solid State Nucl. Magn. Reson. 2018, 95, 1.

${ }^{28}$ O. Nikel, D. Laurencin, S.A. McCallum, C.M. Gundberg, D. Vashishth, Langmuir 2013, 29, 13873.

${ }^{29}$ C. Gervais, C. Bonhomme, D. Laurencin, Solid State Nucl. Magn. Reson. 2020, 107, 101663 and references therein.

${ }^{30}$ Y.H. Tseng, J. Zhan, K.S. Lin, C.Y. Mou, J.C. Chan, Solid State Nucl. Magn. Reson. 2004, 26, 99.

${ }^{31}$ E. Davies, M.J. Duer, S.E. Ashbrook, J.M. Griffin, J. Am. Chem. Soc. 2012, 134, 12508.

${ }^{32}$ P. Cartier, Bull. Soc. Chimie Biol. 1951, 33, 161.

33 J.P Kemp, A. Sayers, W.D. Fraser, G. Davey Smith, M. Ala-Korpela, M.D. Evans, J.H. Tobias, J. Bone Miner. Res. 2019, e3697. 
${ }^{34}$ H.-T. Kwak, S. Prasad, T. Clark, P.J. Grandinetti, Solid State Nucl. Magn. Reson. 2003, 24, 71.

35 Giannozzi, P.; Baroni, S.; Bonini, N.; Calandra, M.; Car, R.; Cavazzoni, C.; Ceresoli, D.; Chiarotti Guido, L.; Cococcioni, M.; Dabo, I.; Dal Corso, A.; de Gironcoli, S.; Fabris, S.; Fratesi, G.; Gebauer, R.; Gerstmann, U.; Gougoussis, C.; Kokalj, A.; Lazzeri, M.; Martin-Samos, L.; Marzari, N.; Mauri, F.; Mazzarello, R.; Paolini, S.; Pasquarello, A.; Paulatto, L.; Sbraccia, C.; Scandolo, S.; Sclauzero, G.; Seitsonen Ari, P.; Smogunov, A.; Umari, P.; Wentzcovitch Renata, M. J. Phys. Condensed matter 2009, 21, 395502.

${ }^{36}$ C.J. Pickard, F. Mauri, Phys. Rev. B, 2001, 63, 245101.

${ }^{37}$ J.P. Perdew, K. Burke, M. Ernzerhof, M. Phys. Rev. Lett. 1996, 77, 3865.

${ }^{38}$ N. Troullier, J.L. Martins, Phys. Rev. B 1991, 43, 1993.

${ }^{39}$ L. Kleinman, D. Bylander Phys. Rev. Lett. 1982, 48, 1425.

${ }^{40}$ C. Gervais, C. Jones, C. Bonhomme, D. Laurencin D. Acta Cryst. 2017, C73, 208.

${ }^{41}$ M.E. Smith, Magn. Reson. Chem. 2020, 1.

42 J. McDonald, Multinuclear Solid State NMR Studies of $\alpha$-Tricalcium Phosphate and Silicon Substituted $\alpha$-Tricalcium Phosphate. Unpublished PhD thesis, University of Warwick, 2012.

${ }^{43}$ K.M.N. Burgess, D.L. Bryce, Solid State NMR 2015, 65, 75.

${ }^{44}$ D. Laurencin, A. Wong, J.V. Hanna, R. Dupree, M.E. Smith, J. Am. Chem. Soc. 2008, 130, 2412.

${ }^{45}$ D. Massiot, F. Fayon, M. Capron, I. King, S. Le Calvé, B. Alonso, J.-O. Durand, B. Bujoli, Z. Gan, G. Hoatson, Magn .Reson. Chem. 2002, 40, 70. 